\title{
Caracterização da galha induzida por ácaro em Laguncularia racemosa (L.) Gaertn (Combretaceae)
}

\author{
Isabela Vieira dos Santos Mendonça ${ }^{1,3}$ \& Jarcilene Silva Almeida-Cortez ${ }^{2}$
}

Biota Neotropica v7 (n3) - http://www.biotaneotropica.org.br/v7n3/pt/abstract?article+bn02607032007

Recebido em 26/02/07

Versão Reformulada recebida em 03/09/07

Publicado em 08/10/07

\author{
${ }^{\text {I} P r o g r a m a ~ d e ~ P o ́ s-G r a d u a c ̧ a ̃ o ~ e m ~ B i o l o g i a ~ V e g e t a l, ~ D e p a r t a m e n t o ~ d e ~ B o t a ̂ n i c a, ~}$ \\ Universidade Federal de Pernambuco, Av. Prof. Moraes Rêgo, s/n, Cidade Universitária, \\ CEP 50670-901, Recife, PE, Brasil \\ ${ }^{2}$ Departamento de Botânica, Universidade Federal de Pernambuco, \\ Av. Prof. Moraes Rêgo, s/n, Cidade Universitária, CEP 50670-901, Recife, PE, Brasil \\ ${ }^{3}$ Autor para correspondência: Isabela Vieira dos Santos Mendonça, e-mail: isabelaic@ gmail.com
}

\begin{abstract}
Santos-Mendonça, I. V. \& Almeida-Cortez, J. Characterization of a mite induced gall in Laguncularia racemosa (L.) Gaerten (Combretaceae). Biota Neotrop. Sep/Dez 2007 vol. 7, no. 3 http://www.biotaneotropica. org.br/v7n3/pt/abstract?article+bn02607032007. ISSN 1676-0603.

Plant galls are formed from abnormal vegetative growth produced by a plant under the influence of an insect, mite, bacteria, fungus or nematode. Galls can be found on any part of the plant, bark, flowers, buds, acorns or roots, but are most often observed as large, swollen growth on a leaf or branch. Our objective was to characterize leaf galls on Laguncularia racemosa (Combretaceae), and the influence of the raining season in its population demography. This study was conducted at mangrove of Maracaípe (Ipojuca, PE). Six sites differing in soil distance from ocean and estuary were chosen for this study. In each site, $30 \times 30 \mathrm{~m}$ plot was established. In each site, 40 leaves with galls from the $2^{\circ}$ or $3^{\circ}$ pair of leaves of different plants were collected, monthly (November/2004 to October 2005). Forty leaves without galls were collected in January (dry season) and July (rainy season) to compare leaf areas. L. racemosa gall is induced by a new species of mite (Acari, Eriophyidae). The gall is green, discoid, and prominent to both leaf surfaces $(1.5 \pm 0.23 \times 1.0 \pm 0.14 \mathrm{~mm})$. We observed an average of $35 \pm 4.4$ $(\mathrm{N}=50$ galls) adults per gall. There was a preferential trend to gall induction next to the leaf apex. The comparison between leaf areas with and without galls presented a significant difference only at the rainy season, when the number of galls was significantly lower, perhaps as a consequence of the higher leaf production during this season and/or due to the restricted mites locomotion caused by the rain.
\end{abstract}

Keywords: Eriopyidae, galls, Mangrove.

\section{Resumo}

Santos-Mendonça, I. V. \& Almeida-Cortez, J. Caracterização da Galha induzida por ácaro em Laguncularia racemosa (L.) Gaertn (Combretaceae). Biota Neotrop. Sep/Dez 2007 vol. 7, no. 3 http://www.biotaneotropica. org.br/v7n3/pt/abstract?article+bn02607032007. ISSN 1676-0603.

As galhas se caracterizam como transformações atípicas de tecidos e/ou órgãos vegetais, podendo ser causadas por ácaros, fungos, nematódeos ou insetos. São resultado de uma íntima associação entre a planta hospedeira e o agente indutor e podem ser induzidas em várias partes da planta. O objetivo deste trabalho foi caracterizar a galha foliar de Laguncularia racemosa (Combretaceae), verificando a influência da sazonalidade na ocorrência da mesma, no município de Ipojuca, PE. O manguezal de Maracaípe foi dividido em seis parcelas $(30$ x $30 \mathrm{~m})$ levando-se em consideração a proximidade com a foz do estuário, cujo sedimento era predominantemente arenoso. Foram realizadas excursões mensais a campo, de novembro/2004 a outubro/2005, para coletar 40 folhas com galhas do $2^{\circ}$ ou $3^{\circ}$ par de folhas expostas ao sol por parcela. Foram, ainda, coletadas 40 folhas sadias $\left(2^{\circ}-3^{\circ}\right.$ par de folhas expostas ao sol/ parcela), em janeiro (época seca) e julho (época chuvosa) para comparar as áreas foliares destas com aquelas das folhas galhadas. A galha foliar induzida por uma nova espécie de Brachendus (Acari, Eriophyidae) em L. racemosa atravessa ambas as faces foliares, tem coloração esverdeada, formato arredondado e comprimento e altura médios de 1,5 $\pm 0,23 \times 1,0 \pm 0,14 \mathrm{~mm}$, respectivamente. Foram encontradas em média $35 \pm 4,4$ ( $\mathrm{N}=50$ galhas) indivíduos adultos por galha. Foi observada uma tendência preferencial do ácaro em induzir galhas próximas ao ápice foliar. A comparação da área foliar entre as folhas galhadas e sadias só apresentou diferença significativa para a estação chuvosa. Neste mesmo período, o número de galhas encontrado é significativamente menor, talvez como uma conseqüência da maior produção de folhas nesta época do ano e/ ou pelo comprometimento da locomoção dos ácaros pelas chuvas. Em geral, as áreas mais próximas à foz do estuário apresentaram significativamente menos galhas que as mais distantes.

Palavras-chave: Eriopyidae, galha, Manguezal. 


\section{Introdução}

Galhas se caracterizam por serem uma transformação atípica de tecidos e órgãos vegetais, em conseqüência da hiperplasia e/ ou hipertrofia de células, tecidos ou órgãos de plantas, podendo ser induzidas por uma grande variedade de organismos, como bactérias, fungos, nematódeos, insetos e ácaros (Mani 1964). Segundo Fernandes \& Martins (1985), as galhas são mais comumente induzidas por insetos, principalmente dípteros e himenópteros. A literatura é rica em trabalhos que abordam esta interação, principalmente sob o ponto de vista descritivo dos táxons envolvidos (Fernandes et al. 1997, 2001, Golçalves-Alvim et al. 2001, Maia \& Fernandes 2004). A relação galha-planta hospedeira é considerada por muitos pesquisadores como parasitária, pois o inseto indutor obtém refúgio e alimento em detrimento do crescimento da planta, perda de substâncias, distúrbio no fluxo da seiva, queda precoce de certas partes vegetais e aumento em quantidade ou volume de órgãos ou tecidos não essenciais a custa dos essenciais (Mani 1964, Silva et al. 1996).

Enquanto considerável atenção tem sido dada para estudos com galhas entomógenas, poucos são os trabalhos que têm investigado os aspectos ecológicos que envolvem galhas induzidas por ácaros (Westphal et al. 1990, 1991, 1992, Ozman \& Goolsby 2005). Os ácaros, principalmente os Eriophyidae (Hossain et al. 2002), são mais popularmente conhecidos por causarem grandes danos como verdadeiras pragas agrícolas e/ou por infestarem plantas ornamentais (Fenton et al. 2000, Knihinicki \& Boczek 2003, Sobhian et al. 2004, Freeman et al. 2005, Bernard et al. 2005). Esta família possui mais de 3.000 espécies de ácaros exclusivamente fitófagos, tendo como características o corpo em formato vermiforme e comprimento médio variando entre 0,15 e $0,30 \mathrm{~mm}$ (Ashihara et al. 2004). Possuem apenas dois pares de patas próximas à cabeça e suas quelíceras são em forma de estiletes (Keifer 1952, Johnson \& Lyon 1988). A maioria é coespecífica a determinadas espécies de plantas e causa nestas algumas injúrias como as galhas, eríneas e desfolhação (Keifer et al. 1982).

O ecossistema manguezal se desenvolve em áreas protegidas da costa em regiões tropicais e subtropicais do mundo (Tomlinson 1986). Sua vegetação possui adaptações únicas que lhes permite ocupar o ecótono entre o ambiente terrestre e o oceano (Cerón-Souza et al. 2005). Dentre os benefícios ecológicos que esse ecossistema proporciona podemos citar: proteção contra a erosão da linha de costa, retenção de poluentes provenientes dos rios, berçário natural para a procriação de diversas espécies, aporte de nutrientes em direção ao mar aberto, etc. (Schaeffer-Novelli et al. 2001). Por ser um ecossistema tão especial, faz-se necessário compreender as interações tróficas entre os organismos adaptados a este ambiente.

Na literatura, são escassos os trabalhos que enfocam a relação galha-planta hospedeira de mangue (Gonçalves-Alvim et al. 2001). Estes autores relacionam uma galha entomógena em Avicennia germinans com o gradiente de salinidade no manguezal analisado. Já estudos referentes a galhas induzidas por ácaros nesse ecossistema ainda são inexistentes. Diante do exposto, o objetivo deste trabalho foi caracterizar a galha induzida por um ácaro na planta hospedeira Laguncularia racemosa (L.) Gaerten (Combretaceae), uma espécie típica de manguezal, em uma área no município de Ipojuca, PE, observando se a sazonalidade influencia a ocorrência da galha.

\section{Material e Métodos}

\section{Caracterização da área de estudo}

O estudo foi realizado no manguezal de Maracaípe (08³2’ 24” S e $\left.35^{\circ} 00^{\prime} 27^{\prime \prime} \mathrm{W}\right)$, município de Ipojuca, litoral sul do Estado de
Pernambuco. O estuário do rio Maracaípe é caracterizado fisiograficamente, segundo a classificação de Cintrón et al. (1985), em bosque de mangue do tipo franja, pois se desenvolve ao longo das margens de costas protegidas, não evidenciando fortes gradientes físico-químicos. A precipitação média e a média térmica dos últimos cinco anos foram respectivamente $175 \mathrm{~mm}$ e $26,7^{\circ} \mathrm{C}$, tendo um período de estiagem que vai de setembro a fevereiro e um chuvoso entre março e agosto (ITEP/LAMEPE). É uma região bastante explorada para o ecoturismo, constituindo-se numa fonte de renda extra para os moradores locais (Sobral 1998).

O Programa GPS TRACKMAKER 12.2 foi utilizado para estimar o tamanho da área do estuário abrangida nesta pesquisa através do georeferenciamento.

\section{Descrição das parcelas}

O manguezal de Maracaípe foi dividido em seis parcelas de $30 \times 30$ m cada (Figura 1) tendo como referência a proximidade em relação à foz do estuário e, ainda, que apresentassem no mínimo 10 indivíduos de L. racemosa. Sendo assim a parcela seis foi a que se encontrava mais próxima à foz, seguida da parcela cinco. Os pontos um, dois e quatro localizaram-se mais ou menos na mesma distância em relação à foz e, por fim, a parcela três foi a mais distante.

Para cada parcela foram coletadas amostras de sedimento a $5 \mathrm{~cm}$ de profundidade em março (época seca) e em junho (época chuvosa) para análises de granulometria e matéria orgânica segundo Suguio (1973). As amostras foram congeladas e armazenadas a fim de serem analisadas no Laboratório de Geoquímica Ambiental do Departamento de Oceanografia e Limnologia da Universidade Federal do Maranhão. Para a caracterização da granulometria, foi utilizado o método de pipetagem para a fração fina do sedimento $(<0,062 \mathrm{~mm})$ e para a fração grossa $(>0,062 \mathrm{~mm})$, o método de peneiramento úmido de acordo com Suguio (1973). Os dados foram analisados segundo o método de Folk \& Ward (1957) no programa Sysgran 3.0, a partir dos quais foram geradas as porcentagens de areia, silte e argila.

A altura da parte aérea dos indivíduos da espécie vegetal estudada (>2 m) nas parcelas foi medida com auxílio de trena, de acordo com a metodologia proposta por Schaeffer-Novelli \& Cintrón (1986). Com o uso do refratômetro, foi estimada a salinidade média do sedimento através de medidas feitas em cada parcela em triplicata a cada ida a campo com o intuito de verificar possíveis variações.

\section{Planta hospedeira estudada}

Laguncularia racemosa conhecida popularmente como mangue-branco, tem ocorrência na porção mediana da zona entremarés das florestas de manguezal da América e África ocidental (Sobrado 2004). Suas principais características diagnosticadas são: um par de glândulas secretoras de sal na parte superior do pecíolo avermelhado (Medina 1999), folhas opostas, pecioladas, espessas e coriáceas, oblongas ou elípticas, com ápices arredondados e emarginados (Tomlinson 1986) e lâminas foliares variando de 4-11 cm de comprimento e 4-5 cm de largura (Schaeffer-Novelli \& Cintrón 1986).

\section{Coleta e análise dos dados}

Foram realizadas excursões mensais a campo de novembro de 2004 a outubro de 2005, a fim de coletar 40 folhas de indivíduos de L. racemosa que apresentassem galhas, em cada parcela, totalizando 240 folhas/mês. Nos meses de janeiro (época seca) e julho (época chuvosa) foram coletadas 40 folhas sadias por parcela para comparação das áreas foliares destas com aquelas das folhas galhadas também coletadas nesses meses. Toda a amostragem do material foliar foi 


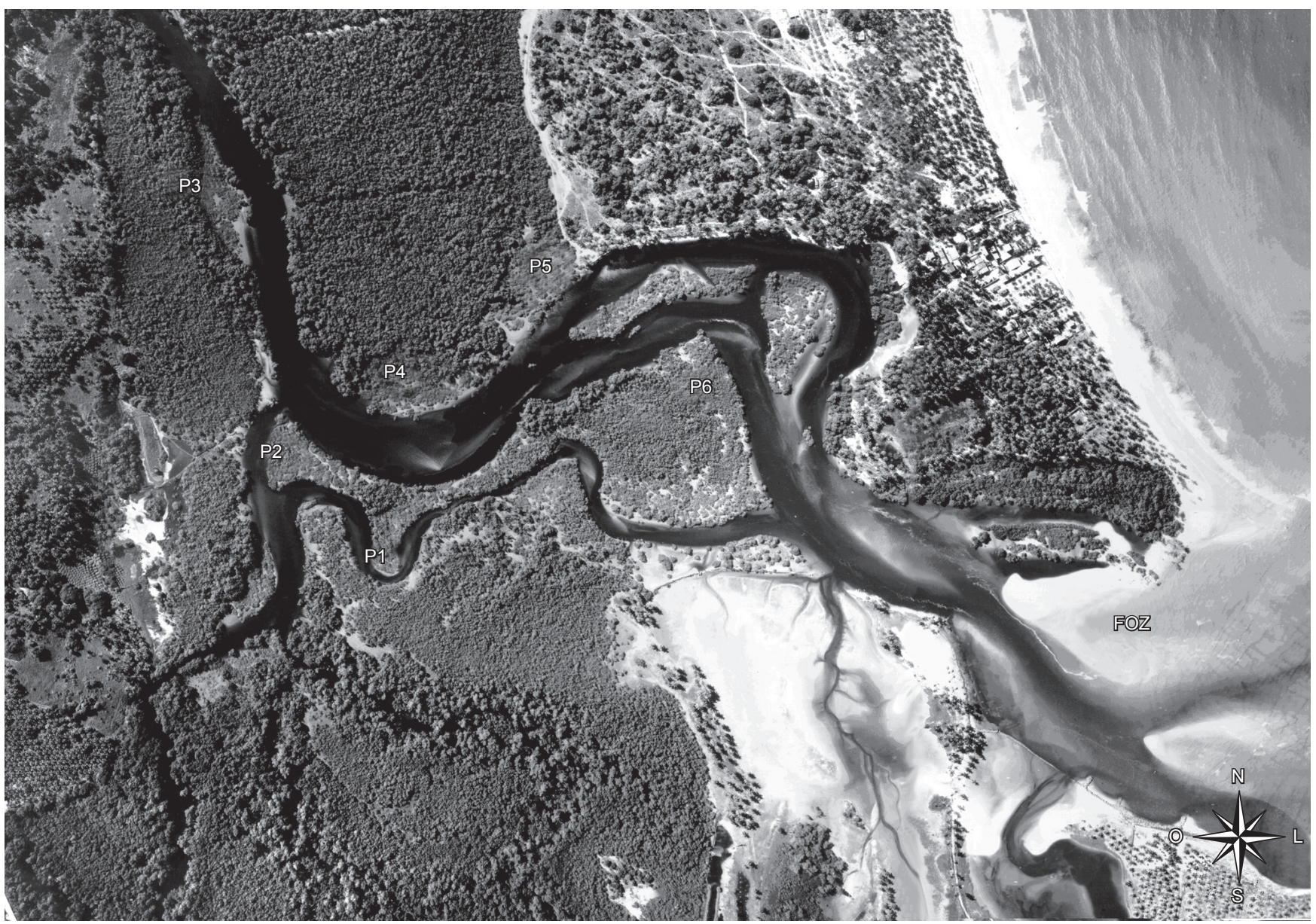

Figura 1. Foto aérea do estuário de Maracaípe, Ipojuca, PE, evidenciando as parcelas delimitadas. Escala: 1: 6000.

Figure 1. Sampling locations at Maracaípe River estuary, Ipojuca, PE. (Aerial photo; Scale 1:600).

feita coletando-se folhas expostas ao sol provenientes do $2^{\circ}$ ou $3^{\circ}$ par de folhas a partir do ápice do ramo, por se constituírem em folhas adultas. Foi observado in situ se as folhas jovens apresentavam galhas a fim de identificar em qual estádio foliar os ácaros induzem a galha e como ocorre o desenvolvimento desta.

Tanto para a época de estiagem (janeiro) quanto chuvosa (julho), todas as folhas coletadas tiveram suas áreas foliares mensuradas através do programa UTHSCSA IMAGETOOL 3.0. Nas folhas com galhas (1) foi estimado o nível de infestação (número total de galhas por coleta); (2) contabilizado o número de galhas presentes nas porções basal, mediana e apical da folha para avaliar se há sítio preferencial de indução; (3) descritas à forma e coloração da galha; e (4) medidos o comprimento e largura destas com o auxílio do paquímetro (caracterização externa). As galhas foram dissecadas sob estereomicroscópio a fim de fazer a descrição interna (número de câmaras ninfais, sua localização e o número de indivíduos por câmara). Lâminas escavadas foram montadas para identificação do indutor.

As análises estatísticas foram feitas através do programa BIOE-TAT 3.0 e a normalidade foi testada pelo Lilliefors. Foram aplicados os testes de Mann-Withney para comparar as áreas foliares e o de Kruskal-Wallis para analisar a distribuição espacial da galha na folha e para a ocorrência de galhas entre as parcelas amostradas. Para o número de galhas encontrado ao longo dos meses utilizouse Anova Two Way. O grau de significância usado foi de $\mathrm{P}<0,05$ (Zar 1999).

\section{Resultados}

\section{Descrição das parcelas}

As parcelas totalizam $5.400 \mathrm{~m}^{2}$ da porção do estuário abrangida por este estudo (próxima à foz), uma área em torno de $329.530 \mathrm{~m}^{2}$. Foi estimado que Laguncularia racemosa ocupa apenas aproximadamente $19.800 \mathrm{~m}^{2}$ do estuário (observação pessoal). A classe granulométrica mais representativa de cada parcela para a época de estiagem e chuvosa encontra-se representada na Tabela 1. Todas as parcelas apresentaram um sedimento predominantemente arenoso, sendo a parcela um (1) e a seis (6) as que possuíram maiores porcentagem de areia dentre as demais nos dois períodos analisados.

A altura média dos indivíduos de L. racemosa amostrados foi de aproximadamente $4 \mathrm{~m}$. A parcela três foi a que apresentou os indivíduos com maiores alturas (Figura 2). Grande parte dos indivíduos presentes nas parcelas cinco e seis caracterizaram-se por estarem em estado regenerativo (troncos em rebrota), podendo ser um indício de ter ocorrido no passado ação de corte da madeira nessas parcelas, fato comum na região para produção de lenha.

$\mathrm{Na}$ época seca, o teor de umidade do sedimento no período de estiagem foi menor em todas as parcelas, com exceção da parcela dois, em relação à época chuvosa (Figura 3). Já a porcentagem de matéria orgânica nas parcelas não variou significativamente entre estas e entre os dois períodos analisados. 
Tabela 1. Classificação granulométrica do sedimento das parcelas nos períodos de estiagem e chuvoso (2004/2005) acompanhado da porcentagem de fração sedimentar mais abundante no Manguezal de Maracaípe, Pernambuco.

Table 1. Grain size classification of the sediment of the plots in the rainy and dry season (2004/2005), followed by the percentage of the more abundant sedimentary fraction in the Mangrove of Maracaípe, Pernambuco.

\begin{tabular}{cll}
\hline Área & \multicolumn{1}{c}{ Período seco } & \multicolumn{1}{c}{ Período chuvoso } \\
\hline Parcela 1 & Areia fina $(100 \%$ areia) & $\begin{array}{l}\text { Areia muito fina } \\
(100 \% \text { areia) }\end{array}$ \\
Parcela 2 & $\begin{array}{l}\text { Silte grosso } \\
(81,22 \% \text { areia) }\end{array}$ & Areia fina $(85,97 \%$ areia $)$ \\
Parcela 3 & $\begin{array}{l}\text { Silte grosso } \\
(67,75 \% \text { areia) }\end{array}$ & Silte grosso $(81,98 \%$ areia) \\
Parcela 4 & $\begin{array}{l}\text { Areia fina } \\
(84,88 \% \text { areia })\end{array}$ & Areia fina $(89,46 \%$ areia) \\
Parcela 5 & Areia fina $(86,2 \%$ areia) & Areia fina $(73,08 \%$ areia $)$ \\
Parcela 6 & areia fina $(99,51 \%$ areia) & Areia fina $(99,77 \%$ areia $)$ \\
\hline
\end{tabular}

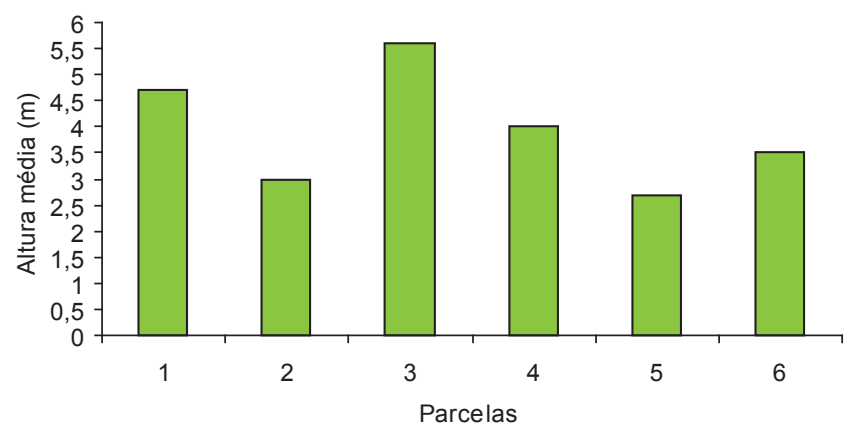

Figura 2. Altura média dos indivíduos de Laguncularia racemosa em cada parcela no manguezal de Maracaípe, Pernambuco.

Figure 2. Medium height plants of Laguncularia racemosa in each plot into the Maracaípe mangrove, Pernambuco.

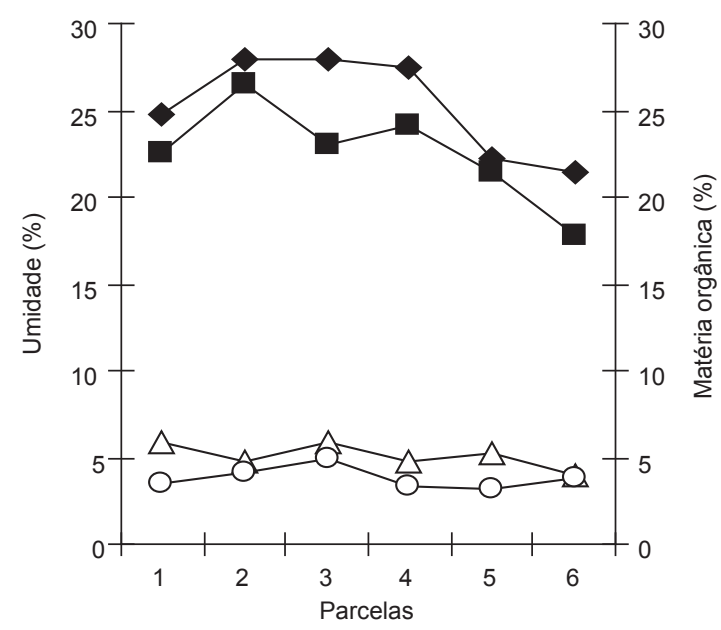

$$
\begin{aligned}
& \longrightarrow \text { Período seco umid (\%) } \begin{array}{l}
\longrightarrow \text { Período chuvoso mat org (\%) } \\
-\triangle \text { Período seco mat org (\%) }
\end{array}-\text { Período chuvoso umid (\%) }
\end{aligned}
$$

Figura 3. Teores em porcentagem de matéria orgânica e umidade do sedimento de cada parcela nos períodos de estiagem e chuvoso (2004/2005) no manguezal de Maracaípe, Pernambuco.

Figure 3. Organic matter and humidity percent of each study area during the rainy and dry season (2004/2005) in each plot into the Maracaípe mangrove, Pernambuco.
A salinidade média dos 12 meses de amostragem estimada para o estuário de Maracaípe foi de 37,8 ppt. Os valores de salinidade do sedimento pouco variaram entre as parcelas ao longo do estudo em cada período (Figura 4). Durante o período de chuva, a salinidade encontrada para o sedimento das parcelas foi significativamente menor $(\mathrm{t}=18,47 ; \mathrm{p}<0,01)$ em relação ao período seco.

Os valores médios de pluviosidade $(\mathrm{mm})$ e de temperatura $\left({ }^{\circ} \mathrm{C}\right)$ durante a realização deste estudo, de acordo com o ITPE/LAMEPE e a Secretaria de Ciência, Tecnologia e Meio Ambiente/ PE, podem ser observados na Figura 5. Nota-se claramente que a pluviosidade durante as amostragens foi mais acentuado para os meses de abril, junho e julho sendo 288, 329, $289 \mathrm{~mm}$, respectivamente. Maio apresentou uma acentuada diminuição na precipitação $(222 \mathrm{~mm})$.

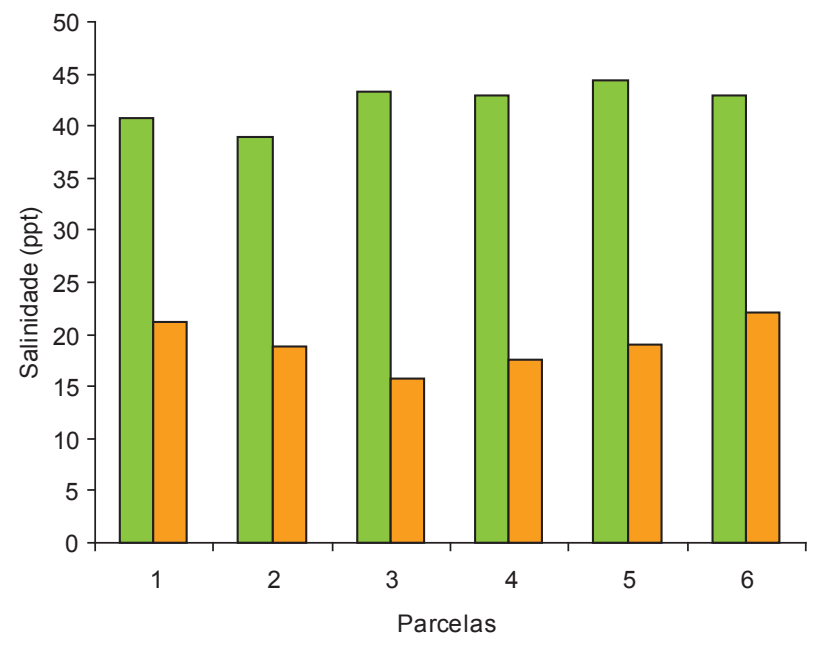

$\square$ Período Estiagem $\square$ Período Chuvoso

Figura 4. Valores de salinidade (ppt) encontrados para cada parcela nos períodos de estiagem e chuvoso (2004/2005) no manguezal de Maracaípe, Pernambuco.

Figure 4. Salinity concentration (ppt) of each study area during the rainy and dry season (2004/2005) in each plot into the Maracaípe mangrove, Pernambuco.

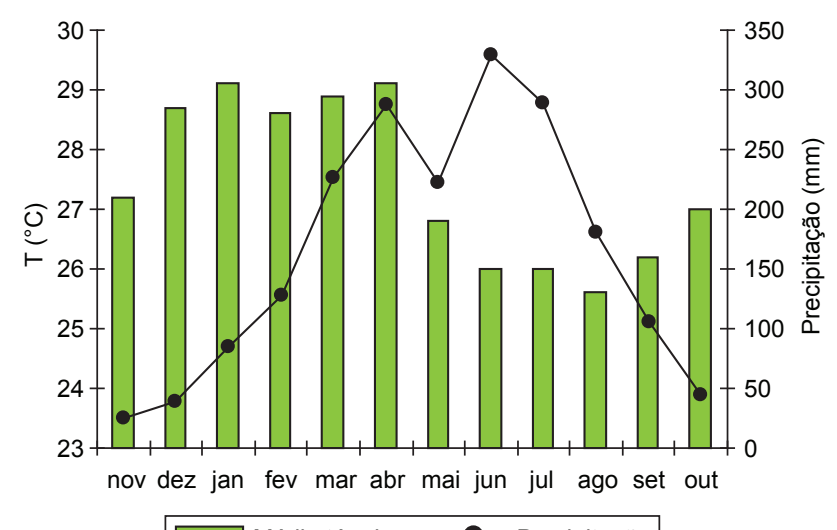

Figura 5. Médias térmicas e de precipitação durante o período de realização do estudo (2004/2005) para o manguezal de Maracaípe, Pernambuco.

Figure 5. Precipitation and temperature media of each study area during the rainy and dry season (2004/2005) in each plot into the Maracaípe mangrove, Pernambuco. 


\section{Caracterização da galha}

Durante a época de observação da parte aérea, Laguncularia racemosa apresentou galhas exclusivamente em folhas, tanto jovens quanto maduras. Foram contabilizadas e analisadas 2.880 folhas com galhas ao longo de um ano de observação. A galha surge como um pequeno espessamento da lâmina foliar, que vai aumentando de volume até assumir o formato discóide quando adulta, estendendo-se da epiderme superior à inferior, atravessando dessa maneira toda a espessura do mesofilo (Figura 6). Pode ocorrer tanto isolada quanto agrupada na folha, sendo esta última situação mais freqüente. A coloração é esverdeada e o tamanho médio de comprimento e altura de $1,5 \pm 0,23 \times 1,0 \pm 0,14 \mathrm{~mm}$, respectivamente.

A abertura das galhas (migração dos ácaros), situação que ocorre quando a folha encontra-se madura (amarelada) ou quando o espaço interno da galha se torna limitado para os indivíduos que aí residem, ocorre em ambas as faces, com maior frequiência na face adaxial $(79,3 \%, \mathrm{~N}=150)$. Foram encontradas uma média de 35 indivíduos/ galha $(\mathrm{N}=50)$, sendo estes tanto adultos quanto juvenis. $\mathrm{O}$ espaço interno da galha possui apenas uma câmara (Figura 7a e 7b).

Há uma tendência preferencial do ácaro em induzir a galha próximo ao ápice foliar $(H=7,25 ; p=0,02$, época de estiagem; $H=15,7$; $\mathrm{p}<0,01$, período de chuvas), conforme pode ser visto na Figura 8 . O número de galhas encontrado para a região apical da folha é muito variável, tanto que o número médio nos períodos seco e chuvoso é respectivamente de 14,4 $\pm 12,9$ e 13,5 \pm 13,3 sendo significativamente maior que o encontrado para a região basal.
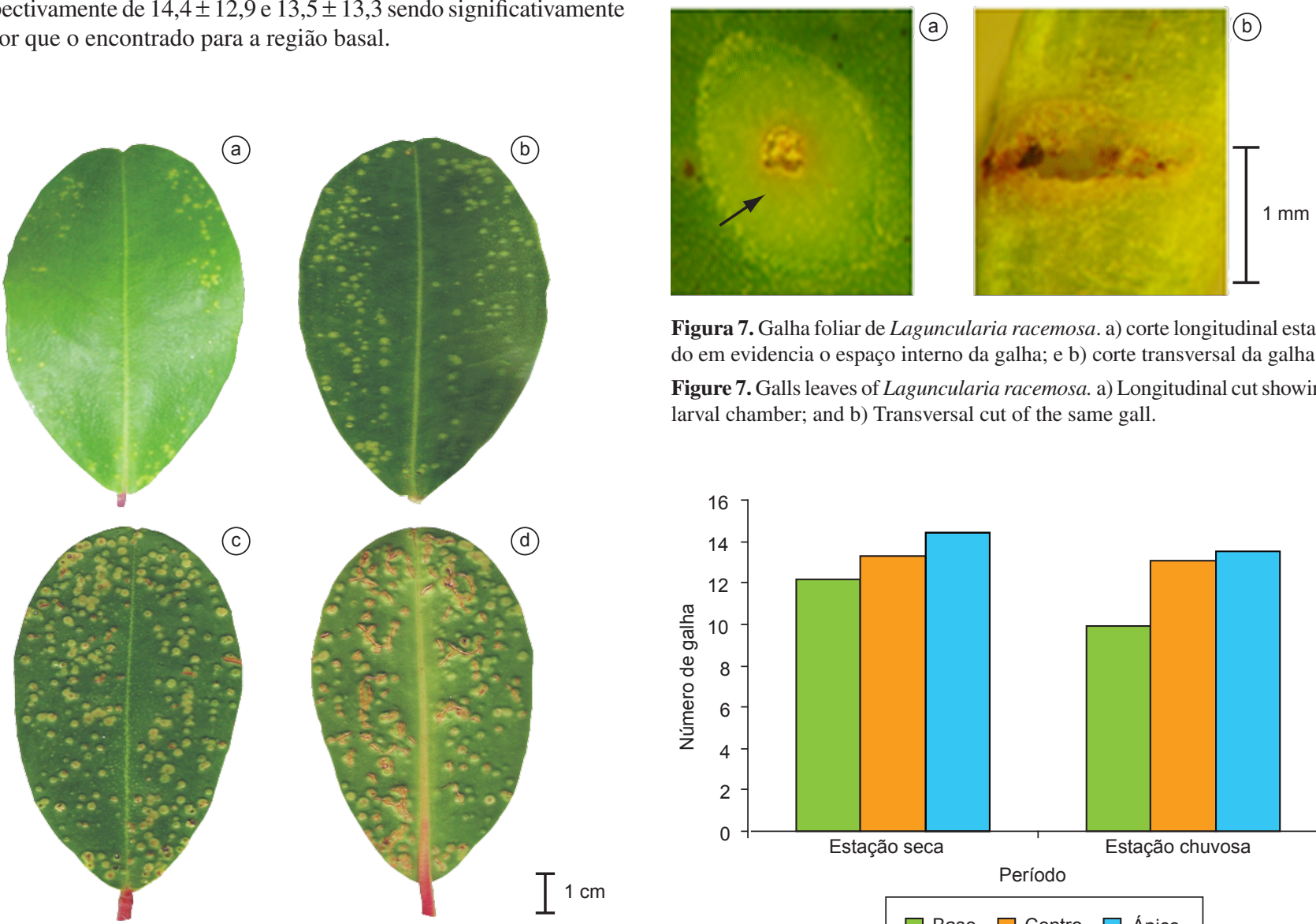

Figura 7. Galha foliar de Laguncularia racemosa. a) corte longitudinal estando em evidencia o espaço interno da galha; e b) corte transversal da galha.

Figure 7. Galls leaves of Laguncularia racemosa. a) Longitudinal cut showing larval chamber; and b) Transversal cut of the same gall.

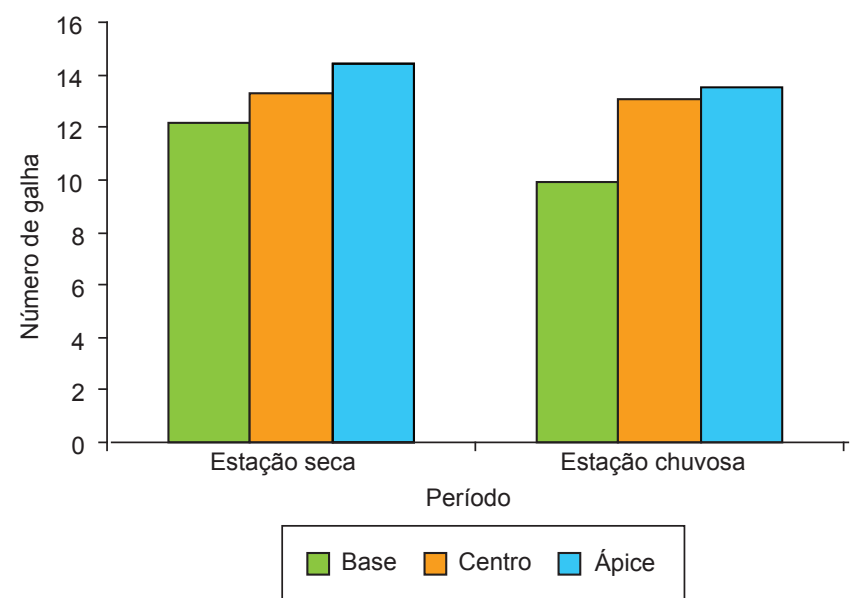

Figura 6. Folhas galhadas de Laguncularia racemosa. a) folha jovem com galhas no inicio do desenvolvimento; b) folha adulta contendo galhas em estádio mais avançado do desenvolvimento; c) face adaxial mostrando as galhas completamente formadas; e d) face abaxial com as galhas já desenvolvidas.

Figure 6. Galls leaves of Laguncularia racemosa. a) New leaf with a young gall; b) Mature leaf with a older gall; c) adaxial leaf blade with a gall; and d) abaxial leaf blade with a gall.

A comparação da área foliar entre a folha galhada $\left(23 \pm 8,1 \mathrm{~cm}^{2}\right)$ e a folha sadia $\left(23,2 \pm 5,6 \mathrm{~cm}^{2}\right)$ não apresentou diferença significativa para a época de estiagem $(\mathrm{Z}=1,1 ; \mathrm{p}=0,26 ; \mathrm{N}=240)$ independentemente do nível de infestação. Entretanto para o período chuvoso ssa diferença é significativa $(Z=39,4 ; p<0,05 ; N=240)$, estando à folha galhada e a folha sadia com áreas foliares de $24 \pm 6,2 \mathrm{~cm}^{2} \mathrm{e}$ $9 \pm 5,9 \mathrm{~cm}^{2}$ respectivamente.

no manguezal de Maracaípe está representada na Figura 9 no qual é observado diferença significativa entre os meses amostrados $\left(\mathrm{F}_{(11,279)}=11,928 ; \mathrm{p}<0,001\right)$.

cela obteve-se o seguinte resultado: apenas nos meses de dezembro, fevereiro e abril, as parcelas não apresentaram diferenças significativas entre si quanto ao total de galhas contabilizado. Os valores estatísticos encontram-se apresentados na Tabela 2 que demonstra tivamente $\left.\left(\mathrm{F}_{(5,279}\right)=9,284 ; \mathrm{p}<0,001\right)$.

\section{Descrição do indutor}

O ácaro indutor da galha em $L$. racemosa pertence a uma nova espécie de Brachendus (Acari, Eriophyidae), B. enodis n. sp. identi-

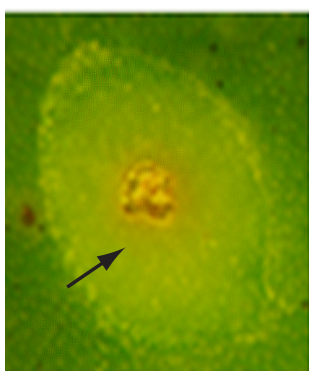

(d)

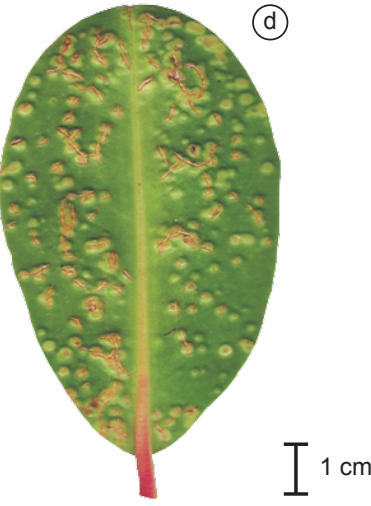

Figura 8. Distribuição espacial da galha nas folhas de Laguncularia racemosa, $\mathrm{N}=240$ nos períodos de estiagem e chuvoso (2004/2005) no manguezal de Maracaípe, Pernambuco.

Figure 8. Spacial distribution of the galls on leaves of Laguncularia racemosa, $\mathrm{n}=240$ during the rainy and dry season $(2004 / 2005)$ in each plot into the Maracaípe mangrove, Pernambuco. 


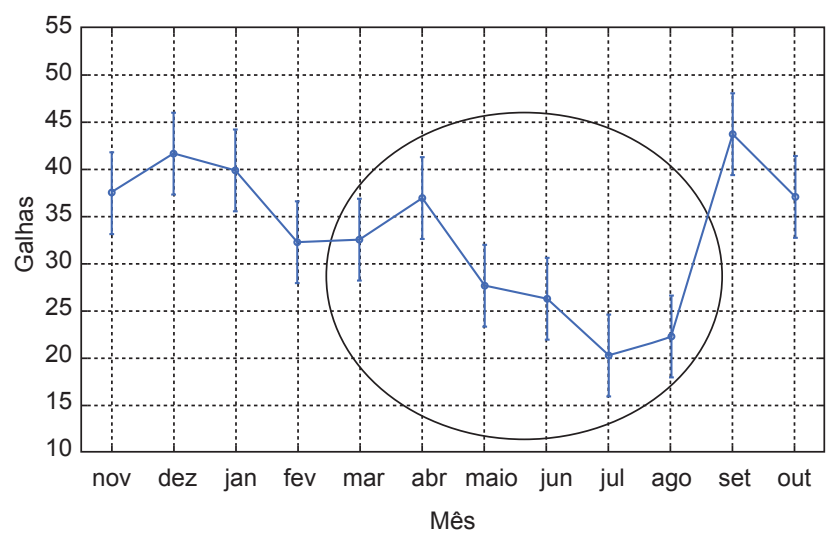

Figura 9. Número médio de galhas encontradas em folhas de Laguncularia racemosa para cada mês de amostragem (2004/2005) no manguezal de Maracaípe, Pernambuco.

Figure 9. Average number of galls on leaves of Laguncularia racemosa, per month (2004-2005) Maracaípe mangrove, Pernambuco.

Tabela 2. Valores significativos do teste Anova two-ways do total do número de galhas em Laguncularia racemosa entre as parcelas amostradas para cada mês estudado (2004/2005) no manguezal de Maracipe, Pernambuco.

Table 2. Significant values of the Anova two-way of the total number of galls in Laguncularia racemosa among the parcels for each month of study (2004/2005) in the mangrove of Maracaipe, Pernambuco.

\begin{tabular}{lrrrrr}
\hline & \multicolumn{1}{c}{ SQ } & \multicolumn{1}{c}{ gl } & QM & \multicolumn{1}{c}{ F } & Valor-p \\
\hline Mês & 152.480 & 11 & 13.862 & 11.928 & $<0.001$ \\
Parcela & 53.950 & 5 & 10.790 & 9.285 & $<0.001$ \\
Mes/parcela & 236.413 & 55 & 4.298 & 3.699 & $<0.001$ \\
Resíduo & 3.248 .198 & 2.795 & 1.162 & & \\
Total & 3.691 .041 & 2.866 & & & \\
\hline
\end{tabular}

ficada por Carlos H.W. Flechtmann. Descrição detalhada da espécie em Flechtmann et al. (2007).

\section{Discussão}

\section{Caracterização da galha e do indutor}

Segundo Mani (1964), 70\% das galhas neotropicais possuem a localização preferencial nas folhas, o que é confirmado por diversos trabalhos com galhas entomógenas (Fernandes et al. 1997, Golçalves-Alvim et al. 2001, Maia \& Fernandes 2004). Isso também é verdadeiro quando consideramos galhas induzidas por ácaros (Keifer et al. 1982) como por exemplo: Phyllocoptes didelphis (Eriophyidae), indudor da galha circular em Populus tremuloides - Salicaceae (Johnson \& Lyon 1988), Vasates quadripedes (Eriophyidae) que causa galhas foliares em Acer rubrum e em A. saccharinum - Aceraceae $\mathrm{e}$, ainda $V$. aceriscrumena (Eriophyidae) que induz galhas em folhas de A. saccharum - Aceraceae (Hoover 2004).

Os ácaros que induzem as galhas são geralmente microscópicos, usualmente amareladas ou quase transparentes, as espécies maiores de ácaros são vistas a olho nu, mas não passam de poucos milímetros. Estes ácaros distinguem-se facilmente das formas não indutoras de galhas (Felt 2001).

A galha em $L$. racemosa se inicia somente em folhas jovens, provavelmente por estas serem mais tenras (Westphal \& Manson 1996; Oldfield 2005). De acordo com a literatura, o processo de formação de uma galha induzida por ácaros se inicia provavelmente através da atividade alimentar da fêmea adulta (Oldfield 2005), que por meio de suas quelíceras modificadas em forma de estiletes, penetram nas células individuais da epiderme dos tecidos da planta (Royalty \& Perring 1996). Essa penetração resulta em uma leve depressão na folha que vai aumentando de tamanho até englobar os ácaros, enquanto que, ao mesmo tempo, ocorre a diferenciação do tecido nutritivo formando a galha (Hoover 2004). Esse tecido nutritivo servirá de sítio de alimentação para os ácaros no interior da galha (Westphal \& Manson 1996). O processo químico da indução parece estar relacionado à liberação de substâncias químicas (reguladores do crescimento) presentes na saliva desses ácaros, durante a alimentação (Lillo \& Monfreda 2004).

Conforme Westphal \& Manson (1996), os ácaros indutores de galhas vivem permanentemente dentro desta, podendo abrigar diversas gerações de ácaros no interior da mesma galha. Esses ácaros, devido ao seu tamanho diminuto e corpo menos protegido contra a dessecação quando comparados aos ácaros fitófagos de vida livre, induzem galhas que servem de abrigo e moradia até que condições estimulem a migração (Royalty \& Perring 1996; Sabelis \& Bruin 1996) como uma estratégia de vida para evitar o ressecamento, criando um microambiente favorável para o seu desenvolvimento na planta (Sabelis \& Bruin 1996). Uma vez a migração estimulada, os ácaros se direcionam para formar novas galhas (Oldfield 2005). Fenton et al. 2000 observaram que esse processo ocorre quando a folha em que a galha se encontra senesce ou quando o espaço interno da galha torna-se limitante para os indivíduos residentes. De acordo com nossas observações a migração do ácaro B. enodis $n$. $s p$. (presente estudo), provavelmente ocorre direcionada ao ápice do mesmo ramo em que a galha madura se encontra para infestar as folhas jovens, uma vez que aproximadamente $100 \%$ dos ramos galhados no início do estudo continuaram a apresentar folhas com galhas após um ano.

Alguns autores, estudando herbivoria foliar causada por ácaros têm comprovado danos nas espécies de plantas como resultado dessa atividade alimentar (Ozman \& Goolsby 2005; Leite et al. 2003). Para $L$. racemosa coletadas no período chuvoso, foi observado que folhas infestadas pelos ácaros galhadores apresentavam uma área foliar menor em relação às demais folhas coletadas. Acreditamos que a presença da galha influenciou o desenvolvimento das folhas. Alguns pesquisadores também têm constatado que a presença da galha pode afetar o crescimento normal das folhas (Westphal \& Manson 1996), no que diz respeito a sua área, como registrado na infestação de Aceria medicaginis (Keifer) em folhas de Medicago sativa I. (Royalty \& Perring 1996).

De acordo com Matioli et al. (1998), diversos fatores como as condições climáticas, tipo e densidade dos tricomas, fertilidade do solo e inimigos naturais, podem influenciar as populações de ácaros nas plantas. Leite et al. (2003), estudando os efeitos da precipitação e da média térmica nas densidades populacionais de três espécies de ácaros fitófagos em Solanum melongena (Solanaceae) no Brasil, encontraram que um clima mais quente e seco favorece o crescimento populacional desses herbívoros.

Pode-se notar em L. racemosa (presente estudo), que durante a época chuvosa (Figura 9; região circulada), tanto a pluviosidade quanto a temperatura parecem influenciar a ocorrência de galhas, uma vez que foi registrado uma diminuição significativa no número de galhas durante esse período, como exemplo, junho, julho e agosto diferiram significativamente de setembro e outubro. Leite et al. (2003) relatam que a precipitação total pode prejudicar o desenvolvimento de ácaros fitófagos. Uma possível explicação seria o fato de que a chuva pode afetar o deslocamento dos ácaros no processo de migração em direção a folhas jovens para a indução de novas galhas, pois, segundo Hoover (2004), o transporte desses herbívoros se dá através do vento, 
aderido a um inseto ou a outros pequenos animais. Outra hipótese seria o aumento da produção de novas folhas que é observado para o período de maior precipitação nas espécies vegetais, não dando tempo de serem infestadas pelos ácaros. Skrzypczynska (2004) encontrou resultados similares estudando a freqüência da população de ácaros indutores de galhas em Populus tremula L. em uma floresta boreal no sul da Polônia.

Ao analisarmos a proximidade das parcelas amostradas com a foz do estuário (Tabela 2) notamos que foi freqüente observarmos as parcelas cinco e seis (as mais próximas) diferirem significativamente quanto ao número de galhas em relação às parcelas consideradas mais distantes da foz (parcelas dois e três), por possuírem menos galhas. Esse fato pode nos indicar que uma menor distância à foz estaria influenciando negativamente a sua infestação. Essa possível influência parece não ser induzida pela salinidade, uma vez que não houve uma grande variação desta entre as parcelas (Figura 4). A maior proximidade com a foz pode acarretar um maior fluxo de corrente pela entrada regular da água do mar afetando o desenvolvimento da espécie vegetal que, por sua vez, refletiria na menor ocorrência da galha estudada neste trabalho.

Algumas espécies de ácaros já foram descritas na literatura como causadoras de galhas em outras plantas presentes no ecossistema manguezal em diferentes regiões do mundo, são elas: Acalitus marinae Smith Meyer que causa galha foliar em Avicennia marina e Aceria avicennniae (Keifer) que induz galhas na inflorescência de $A$. nitida (Amrine \& Stasny 1994). No entanto, pesquisas enfocando aspectos ecológicos destas interações não foram realizadas o que destaca a importância deste trabalho, no que concerne a contribuição para o conhecimento da interação entre um ácaro indutor de galha e uma espécie vegetal típica do ecossistema manguezal.

\section{Agradecimentos}

Agradecemos a dois revisores anônimos pelos comentários e críticas ao artigo.

\section{Referências Bibliográficas}

AMRINE, J.W. \& STASNY, T.A. 1994. Catálogo of the Eriophyoidea (Acarina: Prostigmata) of the world. Indira Publishing House, Michigan, U.S.A., p.798.

ASHIHARA, W., KONDO, A., SHIBAO, M., TANAKA, H., HIEHATA, K. \& IZUMI, K. 2004. Ecology and control of eriophyid mites injurious to fruit trees in Japan. Jarq. 38:31-41.

BERNARD, M., HORNE, P. \& HOFFMANN, A. 2005. Eriophyoid mite damage in Vitis vinifera (grapevine) in Australia: Calepitrimerus vitis and Colomerus vitis (Acari: Eriophyidae) as the common cause of the widespread 'Restricted Spring Growth' syndrome. Experimental and Applied Acarology. 35:83-109.

CERÓN-SOUZA, I., TORO-PEREA, N. \& CÁRDENAS-HENAO, H 2005. Population genetic structure of neotropical mangrove species on the colombian pacific coast: Avicennia germinans (Avicenniaceae). Biotropica. 37:258-265.

CINTRÓN, G., LUGO, E. \& MARTINEZ, R. 1985. Structural and functional proporties of mangrove forests. In. The botany and natural history of Panamá. (W.G. D’Arcy. \& M.D. Cprrea, eds). IV Series: monographs in siystematic botany, vol. 10. Missouri Botanical Garden, St. Louis, Missouri.

FELT, E.P. 2001. Plant galls and gall markers. Agrobios (India). p. 364.

FENTON, B., BIRCH, A.N.E., MALLOCH, G., LANHAM, P.G. \& BRENNAN, R.M. 2000. Gall mite molecular phylogeny and its relationship to the evolution of plant host specificity. Experimental and Applied Acarology. 24:831-861.

FERNANDES, G.W. \& MARTINS, R.P. 1985. Tumores de plantas as galhas. Rev. Ciência Hoje. 4:59-64.
FERNANDES, G.W., ARAÚJO, R.C., ARAÚJO, S.C., LOMBARDI, J.A., PAULA, A.S.DE., LOYOLA, JÚNIOR R. \& CORNELISSEN, T. G. 1997. Insect galls from Savanna and Rock fields of the Jequitinhonha Valley, Minas Gerais, Brazil. Naturalia. 22:221-244.

FERNANDES, G.W., JULIÃO, G.R., ARAÚJO, R.C., ARAÚJO, S.C., LOMBARDI, J.A., NEGREIROS, D. \& VARNEIRO, M.A.A. 2001. Distribution and morphology of insect galls of the Rio Doce Valley, Brazil. Naturalia. 26:221-244.

FLECHTMANN, C.H.W., SANTOS-MENDONÇA, I.V. \& ALMEIDACORTEZ, J.S. 2007. A new species of Brachendus (Acari, Eriophyidae) associated with the white mangrove, Laguncularia racemosa (Combretaceae), in Brazil. Internat. J. Acarol., v 33, n 3.

FOLK R.L. \& WARD W.C. 1957. Brazos River Bay: Study of the significance of grain size parameters. Journal of Sedimentary Petrology. 27:3-27.

FREEMAN, T.P., GOOLSBY, J.A., OZMAN, S.K \& NELSON, D.R. 2005. An ultrastructural study of the relationship between the mite Floracarus perrepae Knihinicki \& Boczek (Acariformes: Eriophyidae) and the fern Lygodium microphyllum (Lygodiaceae). Austr. J. Entomol. 44:57-61.

GONÇALVES-ALVIM, S.J., DOS SANTOS, M.C.F. \& FERNANDES, G.W. 2001. Leaf gall abundance on Avicennia germinans (Avicenniaceae) along an intersticial salinity gradient. Biotropica. 33:69-77.

HOOVER, G.A. 2004. Entomological notes. In College of Agricultural Science, U.S. Departmente of Agiculture, and Pennsylvania Couintes Cooperating. TS -18 .

HOSSAIN, M.A., GAZI, M.M.R., ZAHAN, N. \& DAS, B.C., 2002. Seasonal occurrence of Sissoo Plant Infesting Eriophyid Mite, Aceria dalbergiae Channabasavanna (Acari:Eriophyidae) and Toxicity of Some Insecticides on it. Pakistan Journal of Biological Sciences. 5:1246-1248.

JOHNSON, W.T. \& LYON, H.H. 1988. Insects that Feed on Trees and Shrubs. Second Edition. Ithaca: Cornell University Press.

KEIFER, H.H. 1952. Eriophyid Mites of California. Bulletin of the California Insect Survey. v. 2. $\mathrm{n}^{\mathrm{o}} 1$.

KEIFER, H.H., BAKER, E.W., KONO, T., DELFINADO, M. \& STYER, W.E. 1982. An Illustrated Guide to Plant Abnormalities Caused by Eriophyid Mites in North America. United States Department of Agriculture, Agricultural Research Service. Agriculture Handbook Number 573. p. 178.

KNIHINICKI, D.K. \& BOCZEK, J. 2003. Studies on eriophyoid mites (Acari: Eriophyoidea) of Australia: A new genus and seven new species associated with tea trees, Melaleuca spp. (Myrtaceae). Austr. J. Entomol. 42: 215-232.

LEITE, G.L.D., PICANÇO, M., ZANUNCIO, J.C. \& MARQUINI, F. 2003. Factors affecting mite herbivory on eggplants in Brazil. Experimental and Applied Acarology. 31:243-252.

LILLO, E. DE \& MONFREDA, R. 2004. 'Salivary secretions' of eriophyoids (Acari: Eriophyoidea): first results of an experimental model. Experimental and Applied Acarology. 34:291-306.

MAIA, V.C. \& FERNANDES, G.W. 2004. Insect galls from Serra de São José (Tirandentes, MG, Brazil). Braz. J. Biol. 64:423-445.

MANI, M. 1964. Ecology of plant galls. W. Junk, The Hague, p. 434.

MATIOLI, A.L., LEITE, G.L.D., PALLINI FILHO, A. \& PICANÇO, M. 1998. Distribuição espacial e temporal e efeito de diferentes tratos culturais em ácaros associados a laranja pêra-rio. Agro-Ciência. 14:395-405.

MEDINA, E. 1999. Mangrove physiology: the challenge of salt, heat and light stress under recurrent flooding. In. Ecosystemas de manglar em América tropical. Yánez-Arancibia A. \& Lara-Domínguez A.L. (eds), Instituto de Ecología A.C. Xalapa, México. UICN/ORMA Costa Rica, NOAA/NMFS, Silver Spring, Md.USA, p. 109-126.

OLDFIELD, G.N. 2005. Biology of gall-inducing Acari. In. Biology, ecology and evolution of gall-inducing arthropods. (A. Raman, C.W. Schaefer \& T.M. Withers. eds.). vol. 2. p. 817.

OZMAN, S.K., GOOLSBY, J.A. 2005. Biology and phenology of the eriophyid mite, Floracarus perrepae, on this native host in Austrália, Old 
World climbing fern, Lygodium microphyllum. Experimental and Applied Acarology. 35:197-213.

ROYALTY, R.N. \& PERRING, T.M. 1996. Nature of damage and its assesment. In. Eriophyoid Mites - their biology, natural enemies and control. (E.E. Lindquist, M.W. Sabelis. \& J. Bruin. eds). World Crop Pests. Vol. 6. Elsevier Publishers, Amsterdam, The Netherlands. p. 493-509.

SABELIS, M.W. \& BRUIN, J. 1996. Evolutionary ecology: life history patterns, food plant choice and dispersal. In. Eriophyoid Mites - their biology, natural enemies and control. (E.E. Lindquist, M.W. Sabelis. \& J. Bruin. eds). World Crop Pests. Vol. 6. Elsevier Publishers, Amsterdam, The Netherlands. p. 329-366.

SCHAEFFER-NOVELLI, Y. \& CINTRÓN, G. 1986. Guia para estudos em áreas de manguezal: estrutura, função e flora. São Paulo: Caribbean Ecological Research. p. 150.

SCHAEFFER-NOVELLI, Y., COELHO JUNIOR, C. \& TOGNELLA-DEROSA, M. 2001. Manguezais. Editora Ática, São Paulo-SP.

SILVA, I.M., ANDRADE, G., FERNANDES, G.W. \& LEMOS-FILHO, J.P. 1996. Parasitic Relationships between a gall-forming insect Tomoplagia rudolphi (Diptera: Tephritidae) and its host plant (Vernonia polyanthes, Asteraceae). Annals of Botany. 78:45-48

SKRZYPCZYNSKA, M. 2004. Studies on population frequency of insects and mites causing galls on the leaves of the European aspen Populus tremula L. in southern Poland. J. Pest. Sci. 77:119-122.

SOBHIAN, R., MCCLAY, A., HASAN, S., PETERSCHMITT, M. \& HUGHES, R.B. 2004. Safety assessment and potential of Cecidophyes rouhollahi (Acari, Eriophyidae) for biological control of Galium spurium (Rubiaceae) in North America. J. Appl. Entomol. 128:258-266.
SOBRADO, M.A. 2004. Influence of external salinity on the osmolality of xylem sap, leaf tissue and leaf gland secretion of the mangrove Laguncularia racemosa (L.) Gaertn. Trees. 18:422-427.

SOBRAL, A.O.DE L. 1998. Estudo da erosão marinha na região de Maracaípe Ipojuca. Recife: CPRH, p. 99.

SUGUIO, K. 1973. Introdução à sedimentologia. Edgar Blucher/EDUSP, São Paulo, p. 317.

TOMLINSON, P.B.1986. The botany of mangroves. Cambridge University Press, p. 419.

WESTPHAL, E., DREGER, F. \& BRONNER, R. 1990. The gall mite Aceria cladophthirus 1 . life-cycle, survival outside the gall and symptoms expression on susceptible or resistant Solanum dulcamara plants. Experimental and Applied Acarology. 9:183-200.

WESTPHAL, E., DREGER, F. \& BRONNER, R. 1991. Induced resistance in Solanum dulcamara triggered by the gall mite Aceria cladophthirus (Acari: Eriophyoidea). Experimental and Applied Acarology. 12:111-118

WESTPHAL, E. \& MANSON, D.C.M. 1996. Feeding effects on host plants: gall formation and other distortions. In. Eriophyoid Mites - their biology, natural enemies and control. (E.E. Lindquist, M.W. Sabelis. \& J. Bruin. eds). World Crop Pests. Vol. 6. Elsevier Publishers, Amsterdam, The Netherlands. p.231-242.

WESTPHAL, E., PERROT-MINNOT, M.J., KREITER, S. \& GUTIERREZ, J. 1992. Hypersensitive reaction of Solanum dulcamara to the gall mite Aceria cladophthirus causes an increased susceptibility to Tetranychus urticae. Experimental and Applied Acarology. 15:15-26.

ZAR, J.H. 1999. Biostatistical analisis. Prentice Hall International Inc. Upper Saddle River, New Jersey, p. 660. 